Meta

Journal des traducteurs

Translators' Journal

\title{
Problems and Strategies in Consecutive Interpreting: A Pilot Study at Two Different Stages of Interpreter Training
}

\section{Marta Arumí Ribas}

Volume 57, numéro 3, septembre 2012

URI : https://id.erudit.org/iderudit/1017092ar

DOI : https://doi.org/10.7202/1017092ar

Aller au sommaire du numéro

Éditeur(s)

Les Presses de l’Université de Montréal

ISSN

0026-0452 (imprimé)

1492-1421 (numérique)

Découvrir la revue

Citer cet article

Arumí Ribas, M. (2012). Problems and Strategies in Consecutive Interpreting: A Pilot Study at Two Different Stages of Interpreter Training. Meta, 57(3),

812-835. https://doi.org/10.7202/1017092ar

\section{Résumé de l'article}

Le présent article vise à contribuer à l'étude des compétences stratégiques en interprétation. Après un survol des principaux travaux liés aux concepts de stratégies et aux problèmes en interprétation, nous présenterons une étude pilote qui analyse les problèmes d'interprétation rencontrés par deux groupes d'étudiants à des étapes différentes de leur formation, ainsi que les stratégies utilisées par ces derniers. Les stratégies de résolution de problèmes sont présentées et classifiées, puis est analysée la perception qu'ont les étudiants de leur réussite ou de leur échec, de même que les stratégies qu'ils ont utilisées. Nous avons étudié les traits communs et les différences pour les deux groupes. Nous proposons, en conclusion, que mieux comprendre comment les processus d'interprétation sont acquis et développés nous permettrait de mieux mettre en avant l'élaboration de paramètres de formation qui tiendraient compte des compétences stratégiques et des réflexions pédagogiques. 


\title{
Problems and Strategies in Consecutive Interpreting: A Pilot Study at Two Different Stages of Interpreter Training
}

\author{
MARTA ARUMí RIBAS \\ Universitat Autònoma de Barcelona, Barcelona, Spain \\ marta.arumi@uab.cat
}

\begin{abstract}
RÉSUMÉ
Le présent article vise à contribuer à l'étude des compétences stratégiques en interprétation. Après un survol des principaux travaux liés aux concepts de stratégies et aux problèmes en interprétation, nous présenterons une étude pilote qui analyse les problèmes d'interprétation rencontrés par deux groupes d'étudiants à des étapes différentes de leur formation, ainsi que les stratégies utilisées par ces derniers. Les stratégies de résolution de problèmes sont présentées et classifiées, puis est analysée la perception qu'ont les étudiants de leur réussite ou de leur échec, de même que les stratégies qu'ils ont utilisées. Nous avons étudié les traits communs et les différences pour les deux groupes. Nous proposons, en conclusion, que mieux comprendre comment les processus d'interprétation sont acquis et développés nous permettrait de mieux mettre en avant l'élaboration de paramètres de formation qui tiendraient compte des compétences stratégiques et des réflexions pédagogiques.
\end{abstract}

\begin{abstract}
This article is a contribution to the study of strategic competence in interpreting. After a brief overview of the main contributions dealing with the concept of strategies and problems in interpreting, the article presents a pilot study which analyses the interpreting problems encountered by two groups of students at two different stages of training and the strategies they apply. It details and classifies the strategies used to resolve the difficulties and assesses the students' perception as to whether and how they have successfully completed the task. A number of commonalities and differences between the two groups have been observed. In the conclusions, it is stated that the more we learn about how the processes involved in interpreting are acquired and developed, the more successful we shall be in establishing a basis on which to design training parameters that address the strategic competence and the reflective practice.
\end{abstract}

\section{MOTS-CLÉS/KEYWORDS}

interprétation consécutive, stratégie d'interprétation, problème d'interprétation, étude pilote, questionnaire rétrospectif

consecutive interpreting, interpreting strategy, interpreting problem, pilot study, retrospective questionnaire

\section{Introduction}

Consecutive interpreting entails a large number of almost concurrent cognitive, psychomotor and affective processes, all of which pose major challenges for the interpreter who has to deal with them simultaneously. The interpreter is constantly confronted with unexpected situations that must be dealt with while he/she is already working at the limits of his/her available processing capacity (Gile 1995). It 
is therefore crucial that interpreter training should be as effective as possible and that during their training period, future professional interpreters should develop a series of strategies or tactics that can be used to solve the problems encountered. Gile (1995; 2009) describes a series of tactics and strategies interpreters apply when problems in the interpreting process arise. He establishes a distinction between the terms tactics and strategies. According to this author, strategies are planned actions with specific objectives and tactics refer to online decisions and actions taken by the interpreter during the execution of the task to overcome the difficulties encountered. He restricts the use of these two terms to deliberate decisions and actions aimed at preventing or solving problems. In the present study, we prefer to use the term strategy to refer to both immediate and longer-term actions taken to solve a problem. At the same time, as we shall see in the results of the study, and bearing in mind that our analysis is based on a retrospective reflection by the students after having completed a task, it is impossible to determine whether the strategies adopted by the students when faced with an interpreting problem are conscious and deliberate, or whether they are unconscious, spontaneous actions and reactions in response to a difficulty.

Interpreting quality depends on certain skills and strategies that need to be acquired over time, usually as part of a university training programme. One issue that is central to the question of what makes a good interpreter, and is closely related to the interpreter training, is the question of how the interpreting output of experts and novices differs, both in terms of quality and processing (Sunnari 2003). In this sense, a number of studies have been carried out in the field of teaching interpreting which define how the evolution from novice to expert interpreter takes place. Hoffman (1997) and Moser-Mercer, Frauenfelder et al. (2000) stress that the development of expertise happens in different phases, as students progress from a cognitive stage, through an associative stage to an autonomous stage. In translation and interpreting novices still need to engage in tactical learning whereby they learn specific rules for solving specific problems. This tactical knowledge then becomes increasingly well organised and the novice develops a set of strategies designed to optimally solve the problems he/she encounters (Moser-Mercer, Frauenfelder et al. 2000: 110). It is worth noting the prominent position that strategic competence has come to occupy in recent thinking about the acquisition of interpreting expertise and the fact that some authors (Ericsson 2001; Moser-Mercer, Frauenfelder et al. 2000) point to strategic ability as an indication of expert knowledge in interpreting. According to Moser-Mercer (1997: 194), research on the interpreting process needs to go further, addressing not only the knowledge structures, but, more particularly, the dynamic nature of their application during the interpreting process.

However, following Hurtado (2001: 276), despite their fundamental importance concerning the key role of operative knowledge in translation and interpreting, studies which examine translation and interpreting strategies are still in their infancy. Gile (2000: 81) similarly stresses that there are very few studies that describe strategic processes in interpreting.

This study aims to identify some general patterns in the emergence of problems and strategies reported by students at two different stages of training in consecutive interpreting. Furthermore, it analyses the students' perceptions concerning their ability to resolve interpreting problems. Finally, the study evaluates whether the questionnaire used is a suitable method for studying the strategic component in interpreting. 
The results presented are descriptive and were obtained from the analysis of a post-interpreting questionnaire answered by the students. It is, therefore, a pilot study whose purpose is to approach the subject on the basis of the information provided by the individual students who participated in the study. It should be pointed out that the questionnaire was not specifically designed for the purpose of the research, but was previously used by the researcher (who is also a teacher of interpreting) as a didactic instrument in the interpreting classroom. It was as a result of observing how students were prompted by the questions in the questionnaire to reflect in detail on the problems they had encountered in their interpreting tasks and how they had solved them that we decided to undertake the present study to monitor the observable patterns in the data obtained. We study the problems reported by two groups of interpreting students (beginners and advanced) when carrying out an exercise in consecutive interpreting. We also set out to identify the strategies reported by the two groups of students in solving the problems detected. Another objective of the study is to observe the usefulness of the post-interpreting questionnaire in research on this topic.

As stated by Riccardi, "conference interpreting is no longer merely considered an implicit competence, a skill difficult to explain and put into words and whose teaching is even more difficult, if not impossible" (Riccardi 2005: 757). It is also a form of declarative knowledge, rising into consciousness, which can therefore be verbalized. Accordingly, if we succeed in understanding how the processes involved in the exercise of interpreting are acquired and developed, we shall be able to lay the foundations for designing training parameters which take strategic competence into account.

\section{Translation and Interpreting Strategies}

The concept of strategy was first introduced in the field of translation by Hönig and Kussmaul (1982), who defined translation strategies as processes which lead to an optimum solution to a translation problem. Hurtado (1999: 246) defines translation strategies as the individual procedures, both conscious and unconscious, verbal and non-verbal, used by the translator to solve the problems encountered in the course of the translation process, depending on the specific requirements involved.

Regarding the problems, according to Nord (1988: 151), these are objective difficulties that all translators need to resolve during a given task, regardless of their level of competence and formal working conditions. Riccardi (1998) states that simultaneous interpreting can be considered a problem-solving activity. The difficulty arises from the original speech, while the solution occurs in the interpreted speech, and the strategies consist in the mechanisms and decisions that take place between the problem and its solution.

Returning to the concept of strategy, Hurtado (2001: 277) states that translation strategies may be linguistic, extralinguistic, instrumental or pragmatic. Attempts have been made to analyse translation strategies by means of experiments. The main methodological approach used has been think-aloud protocols, that is, where the translator (or translation student) expresses his/her mental processes while translating. Some noteworthy studies along these lines include those by Lörscher (1991) and Kiraly (1995). In other cases software such as Camtasia and Proxy were used. They 
allow the translation process to be recorded and to view the steps taken by the translator, namely, corrections, consulting document sources and modifications. On the other hand, the software Translog (Jakobsen 2011), in addition to recording the translation process, also provides time statistics, pauses by the translator, behaviour, etc. Thus it is possible to obtain data in a more natural setting. Finally, not to be forgotten are the eye-tracking systems, which record eye movements of the translator across the screen.

Lörscher (1991: 125) considers a translation strategy to be a conscious and individual process used to solve a translation problem. Therefore, translation strategies are individual; they entail an element of planning, pursue certain objectives and are associated with a series of actions taken in the pursuit of achieving those objectives. He organizes strategies into three global strategies:

- propose preliminary solutions to problems (explore);

- literally repeat source or target text segments that have already been captured or verbalised (control);

- recoup segments and reformulate them (paraphrase).

He also underlines the wide variety of strategies used. In other words, different strategies are used by different subjects to deal with the same problem. However, he only considers translation problems of a lexical, syntactic or lexico-syntactic nature.

The study by Kiraly (1995) presents a series of translation process indicators, including dictionary query strategies, the use of mnemonic devices, retranslations, etc. However, there are drawbacks to both Lörscher (1991) and Kiraly's (1995) studies regarding their general assertions about translation strategies. Lörscher's study focuses on foreign language students and consequently deals with pedagogical translation rather than professional translation, extrapolating from students engaged in pedagogical translations to professionals who carry out communicative translation. Kiraly studies a group of nine translators and nine translation students, which is a rather small sample.

As shown by the studies reviewed, analysing the strategic component in interpreting is considered to be a fundamental source of relevant data for teaching. Abuín (2007) provides an exhaustive review of the most prominent strategy-related studies in the field of interpreting, which we shall now briefly consider.

Gile $(2002 ; 2009)$ analyses interpreting problems and strategies through his Effort Model. ${ }^{1}$ In this Model, Gile talks about processing capacity, which is finite and which enables us to see the errors in the interpretation process and propose solutions to these difficulties. Kalina $(1998 ; 2000)$ has also made noteworthy contributions with her notions of strategy, strategic processing and interpreting competence. Kohn and Kalina (1996: 126) point out that interpreting can be explained from its strategic dimension, in the sense that it constitutes a speech that is strategically processed and produced with the objective of facilitating the interlinguistic transfer of mental models which have been created on the basis of a source and target speech. Kalina uses the term strategy in the broad sense to refer to the text processing and production operations performed by the interpreter during the reception and/or production of a speech. Kalina $(1994 ; 2000 ; 2002)$ also makes a methodological contribution to the gathering and analysis of empirical data on the interpreting process. Thus, in her study published in 1994, Kalina provides practical and general information on gathering an audio interpreting corpus and concludes that, given the diversity of the 
existing criteria for transcribing oral material, in the case of an interpreting corpus the selection criteria should be the most appropriate to the proposed object of study. It is particularly important to use the introspective methodological tool of the thinkaloud protocol, which allows a subject's comments while performing a specialized task to be monitored. Kalina adapts this method of introspective verbalisation to the specific circumstances of interpreting, transforming it into a retrospective tool applied at the end of the process to obtain verbal data from interpreters about the difficulties encountered and the strategies used during the interpreting task. Similarly, Riccardi (1996) studies the difficulties encountered and the solutions brought to bear by interpreters with differing degrees of experience as they tackle a simultaneous interpreting task. From a more theoretical point of view, Riccardi (1998) has reflected on the creative component in interpreting strategies. In her study published in 1999, Riccardi emphasises that there are general strategies, which are applicable to all language combinations, and specific strategies applicable to the individual language pairs in question. Riccardi (2005) distinguishes between comprehension, production, overall and emergency strategies. Comprehension strategies generally include anticipation, segmentation, selection of information, stalling or waiting, while production strategies consist of compression, expansion, approximation strategies, generalisation, use of linguistic open-end forms, morphosyntactic transformation and the use of prosodic elements, such as pauses and intonation. Décalage and monitoring are counted among overall strategies, while emergency strategies may include, for example, the omission of text segments, transcoding and parallel reformulation.

Ivanova (2000) makes a methodological contribution to the study of strategic competence in interpreting by examining the limitations and the possibilities involved in using retrospective, or post-task, verbalisation instruments in processbased studies. She explores the use of retrospective protocols for investigating the cognitive processes mediating performance during simultaneous interpreting. She showed that applying the methodology of delayed retrospection to SI requires careful design and manipulation of different types of memory support for retrospection. Instructing the subjects to verbalise segment by segment and giving them the opportunity to initiate the retrospection can elicit interesting data.

Other important studies include those by Sunnari (1995; 2003), which present the results of using macro-processing or synthesis strategies in simultaneous interpreting. It is the author's hypothesis that macro-processing is one of the key strategies leading to a fluent simultaneous interpretation. She states that an ability to apply macro-strategies (synthesis, summarising, elimination of redundant or superfluous information) not only qualifies the task of the interpreter, but also determines the quality of the interpretation.

Gran (1998) presents the results of an empirical study on reformulation strategies used by professional interpreters and interpreting students. In her application of the results to training, the author advocates a gradual approach to the acquisition of simultaneous interpreting skills beginning with exercises training one skill at a time, such as text analysis, abstracting, paraphrasing, and subsequently moving over to the whole task. At a later stage, training will be devoted to particularly difficult or complex parts of the interpreting process - the speaker's pronunciation, speed of delivery, density of information, specialized terminology, rhetoric. 
Another particularly helpful study is that of Abuín (2007), which offers an indepth analysis of the various approaches to studying the problem-strategy relationship. Moreover, the study presents a classification of the corresponding problems and strategies, both during the reception of the message in the original language and the production of the message in the target language.

\section{The study}

\subsection{Objectives}

As mentioned earlier, a review of the literature on this subject clearly shows the importance of studying the problem-strategy relationship in interpreting according to different degrees of experience (Moser-Mercer 1997; Kalina 2000; Abuín 2007). Generally speaking, available published studies have focused on researching the differences between novices and professional experts, and have left aside the differences at different stages of training. Furthermore, as stated by Gile (2000: 81), there are few studies which describe the strategies via observation methods and think-aloud protocols. In response, this article attempts to make a contribution to this field by focusing on two distinct phases in interpreter training. The study is based on the following objectives:

- analyse which problems novice and advanced students detect in consecutive interpreting;

- study the students' perceptions concerning their ability to resolve interpreting problems;

- analyse which strategies novice and advanced students report in consecutive interpreting;

- study whether there are differences between groups at different stages in their training;

- evaluate whether the post-interpreting questionnaire used is a suitable method for studying the strategic component in consecutive interpreting.

\subsection{Subjects}

The initial sample size was 26 subjects at two different levels (novice and advanced) of university training in Spain. 16 questionnaires were answered by novice students (Universitat Pompeu Fabra - UPF) and 10 questionnaires were answered by advanced students (Universidad de La Laguna - ULL). No selection was carried out on the sample and all the students in the two groups were taken into consideration. Of the 26 questionnaires returned, 11 were discounted because they were incomplete, that is, a one third or more of the questions were not answered. To be precise, 8 incomplete questionnaires were discounted in the case of Universitat Pompeu Fabra, while 3 were discounted in the case of Universidad de la Laguna. Thus, the corpus consists of a total of 15 students, of whom 8 are beginners and 7 are advanced. Regarding the distribution of the questionnaires, in the case of the novice students the researcher distributed the questionnaires personally, while in the case of the advanced students the questionnaires were distributed by post after the objectives of the research had been discussed with the coordinator of the Master's programme. Once completed, the questionnaires were returned to the researcher by post. 
The two levels of training studied are representative of the organization of university interpreting courses in Spain, which are currently offered at the undergraduate and postgraduate levels.

On the one hand, we studied a group of undergraduate students; to be more precise, the students were taking introductory practical classes in consecutive interpreting during the third year in their undergraduate degree programme, entailing some 40 hours of practical sessions, and having received no previous training in interpreting. Bearing in mind that this is a compulsory subject in the Translation and Interpreting Licenciatura ${ }^{2}$ in Spain, the group includes a wide range of students, from those who wish to further their training in the field of interpreting to students who intend to work as translators and therefore have no particular interest in interpreting itself.

On the other hand, we studied a group of postgraduate students who had attended approximately 300 hours of practical sessions during five months of classes, in addition to a prior B.A. and/or professional experience in other areas. These students were admitted to a Master's course in interpreting after having passed an entrance test and, since they were enrolled in a postgraduate training programme, we assumed that the students were committed to pursuing a career in interpreting at the end of their course.

\subsection{The experiment}

Although the question of deciding on the material to be used in conducting the experiment is a controversial one (Orozco 2000: 148), the original speech (see Appendix 1) was selected bearing in mind that, as the subjects were students still undergoing training, the use of authentic material would not be appropriate if the experiment was to ensure a degree of complexity suitable for both groups. For similar reasons, we chose to pre-record the speech in order to limit the speed of delivery.

For the experiment, students were first asked to fill in an initial questionnaire, asking for general information about the students. Immediately afterwards, the subjects performed an English-Spanish consecutive interpreting exercise (English being the $\mathrm{C}$ language of the students and Spanish, the A language) and then filled in a second questionnaire, or post-interpreting questionnaire. Before playing back the speech to the students, the class instructor read out an introduction to the topic that they had been given, along with instructions on how to perform the exercise. The students completed the exercise individually, one after the other, without having the opportunity to listen to the versions of their classmates. The students took notes, audio recordings were made of their performances, and immediately afterwards they were given the post-interpreting questionnaire. A possible lack of motivation on the part of the subjects to participate in the experiment was offset by the presence of an audience (other students from the institutions concerned were invited to attend), who listened to the Spanish version given by the interpreters. 8-15 students from other class groups were present during all the interpreting students' performances. The notes were compiled, together with the recordings of their performances. 


\subsection{Data collection}

Applying empirical research to interpreting is subject to a number of limitations. On the one hand, in practice, the introspective method (e.g. think aloud protocols) is not viable, due to the physical impossibility of interpreting at the same time as talking about something else. Authors such as Fraser (1996) and Kalina (1994) point out the need for validation techniques to ensure that the material verbalised corresponds to cognition during the process. Nor are retrospective methods without their drawbacks. In this sense, Fraser (1996) stresses the impossibility of recalling automatic cognitive processes which leave no trace in the subject's memory and which cannot, therefore, be verbalised. Moreover, there may be some confusion in the subjects' minds between what they have actually done and what they believe they have done, which poses a problem of validity related to self-perception. Bearing in mind all these considerations, a questionnaire was applied at this stage of the research, in which our main aim was to obtain preliminary data through a pilot study. The retrospective method has been used in research on the interpreting process in a number of cases (Kohn and Kalina 1996; Jiménez Ivars 1999; Ivanova 2000; Abuín 2007), although typically as a complementary instrument in the verification of results.

In our study, two questionnaires were used:

- An initial questionnaire (see Appendix 2), specially designed for this research. It included questions about the students' profile (age, gender, languages, first language, training and professional experience).

- A post-interpreting questionnaire about the interpreting task (see Appendix 3), which had previously been used by the researcher as a tool for reflecting on learning strategies in the classroom and which she now introduced as a data collection instrument for the purpose of her research. It included two types of question. Some were open-ended (eliciting information about how useful the instructor's introduction to the topic had been, previous knowledge about the topic, concentration and memory-related problems, satisfaction with the presentation). Others were of a more closed nature and were concerned with the degree of difficulty perceived by students in each of the consecutive interpreting phases ${ }^{3}$ (reception phase and production phase) according to different parameters (speed, subject matter, terminology, structure, etc.). The notes taken by the students were compiled for reference purposes to check comments about strategies used when taking notes or reproducing them.

The data were collected between January and March of 2005, coinciding with the previously mentioned stages of training.

\subsection{Data analysis}

The first step in the analysis consisted of grouping together the questions about the difficulties encountered during the consecutive interpreting phases and how the subjects had dealt with these difficulties, and questions about secondary considerations. The answers to the initial questionnaire were used to check the profile of the subjects: training, first language and experience.

The following analysis protocol was used to study the interpreting problems and strategies: 
1. Compile a content analysis table containing the answers of each student to the questions in the post-interpreting questionnaire, as well as the researcher's analysis of those answers and the abstraction and concretion in problems and strategies. A few examples may be seen in Table 1.

2. Draw up a comprehensive list of all the difficulties and strategies that appear in the post-interpreting questionnaires from both groups.

3. Carry out an univariate analysis with frequency tables for problems and strategies for each of the consecutive interpreting phases and each of the groups. Furthermore, the percentages in respect of the total number of students in each category and in respect of the total in each group have also been included.

4. Carry out a bivariate analysis with contingency tables in order to describe the proposed solution in both groups.

TABLE 1

Example of content analysis

\begin{tabular}{|c|c|c|c|c|c|c|}
\hline $\begin{array}{l}\text { Subject } \\
\text { and unit } \\
\text { of analysis }\end{array}$ & Description & $\begin{array}{l}\text { What was } \\
\text { the problem } \\
\text { due to? }\end{array}$ & $\begin{array}{l}\text { What did you } \\
\text { do? }\end{array}$ & $\begin{array}{l}\text { Did you } \\
\text { solve the } \\
\text { problem? }\end{array}$ & Problems & Strategies \\
\hline $012-3.2$ & $\begin{array}{l}\text { I didn't get the } \\
\text { percentage of } \\
\text { birds } \\
\text { mentioned in } \\
\text { the speech. }\end{array}$ & $\begin{array}{l}\text { I find it } \\
\text { "very" hard } \\
\text { to get the } \\
\text { numbers } \\
\text { right, it takes } \\
\text { more effort. }\end{array}$ & $\begin{array}{l}\text { I said: "the } \\
\text { remainder" } \\
\text { because I had } \\
\text { grasped the } \\
\text { other two. }\end{array}$ & Yes & Numbers & Generalisation \\
\hline $008-4.1$ & $\begin{array}{l}\text { Inability to } \\
\text { note down all } \\
\text { the } \\
\text { information. }\end{array}$ & $\begin{array}{l}\text { Lack of } \\
\text { note-taking } \\
\text { practice }\end{array}$ & $\begin{array}{l}\text { I worked more } \\
\text { quickly and } \\
\text { noted down } \\
\text { what I really } \\
\text { was sure of. } \\
\end{array}$ & $\begin{array}{l}\text { Not very } \\
\text { well }\end{array}$ & $\begin{array}{l}\text { Lack of } \\
\text { note-taking } \\
\text { practice }\end{array}$ & Omission \\
\hline $007-5.2$ & $\begin{array}{l}\text { The ideas } \\
\text { don't hang } \\
\text { together } \\
\text { coherently. }\end{array}$ & $\begin{array}{l}\text { Lack of } \\
\text { connectors }\end{array}$ & $\begin{array}{l}\text { Tried to apply } \\
\text { logic }\end{array}$ & Sometimes & $\begin{array}{l}\text { Lack of } \\
\text { connectors }\end{array}$ & $\begin{array}{l}\text { Used common } \\
\text { sense }\end{array}$ \\
\hline 002-3.4 & $\begin{array}{l}\text { I didn't } \\
\text { understand } \\
\text { the proposal } \\
\text { of the WTO. }\end{array}$ & $\begin{array}{l}\text { Lack of } \\
\text { knowledge }\end{array}$ & $\begin{array}{l}\text { I concentrated } \\
\text { on the } \\
\text { elements I did } \\
\text { understand. }\end{array}$ & More or less & $\begin{array}{l}\text { I didn't } \\
\text { understand. }\end{array}$ & Summarise \\
\hline 003-3.2 & "Worshipped" & $\begin{array}{l}\text { I couldn't } \\
\text { think of the } \\
\text { Spanish } \\
\text { equivalent. }\end{array}$ & $\begin{array}{l}\text { I noted it } \\
\text { down in } \\
\text { English. }\end{array}$ & $\begin{array}{l}\text { I think I } \\
\text { changed the } \\
\text { sense too } \\
\text { much. }\end{array}$ & $\begin{array}{l}\text { Problems of } \\
\text { equivalence }\end{array}$ & Paraphrase \\
\hline $007-5.1$ & $\begin{array}{l}\text { Difficulty } \\
\text { recognizing } \\
\text { some } \\
\text { concepts. }\end{array}$ & $\begin{array}{l}\text { Illegible } \\
\text { writing }\end{array}$ & $\begin{array}{l}\text { Relied more } \\
\text { on my } \\
\text { memory and } \\
\text { less on my } \\
\text { notes. }\end{array}$ & $\begin{array}{l}\text { I'm working } \\
\text { on it. }\end{array}$ & $\begin{array}{l}\text { Unclear } \\
\text { notes }\end{array}$ & Memory \\
\hline
\end{tabular}

With reference to the interpreting problems, the students' ability to solve the problems occurring in each of the consecutive interpreting phases was evaluated by group, and then both groups were compared. Based on the list of difficulties generated, a comparative analysis of the problem-solving strategies used for each case was carried out and followed by a cross-group comparison.

All results have been obtained with the statistical software SPSS for Windows, version 17. 
When considering the tables presented, both in the case of the problems and the strategies, it should be borne in mind that a given student may have perceived more than one problem and applied more than one strategy.

\section{Results}

The results were analysed from the perspective of the objectives proposed at the outset, that is, first the interpreting problems the students detected during the activity, followed by an analysis of the strategies they reported after performing the interpreting exercise.

\subsection{The interpreting problems}

First of all, it should be noted that since we are dealing with the training phase, we do not only understand the problems as objective difficulties as defined in section 3 when talking about the theoretical concept, but also consider the perceptions of the students to look at the larger number of strategies they use to negotiate their difficulties.

The problems reported by students from both groups are listed below, broken down according to each of the interpreting phases: listening and understanding, note-taking, decoding notes and expressing and reformulating. The objective here is not to offer an in-depth classification, and the problems clearly belong to different categories: from problems directly related to the interpreting task to those directly related to the abilities of the subjects. The total number of problems gathered from the advanced group post-interpreting questionnaires is appreciably lower than those from the novice group, although the latter included one more subject.

TABLE 2

\section{General breakdown of interpreting problems}

\begin{tabular}{|l|}
\hline Listening and Understanding \\
\hline Lack of understanding of the source speech \\
Numbers \\
Lack of common sense \\
Speed of delivery of the source speech \\
Unfamiliarity with the topic \\
Sound problems \\
Length of the source speech \\
Information density \\
Lack of practice \\
Lack of attention/concentration \\
\hline Note-Taking \\
\hline Lack of understanding of the source speech \\
Speed of delivery of the source speech \\
Information density \\
Lack of practice \\
Numbers \\
\hline Decoding Notes \\
\hline Unable to understand their own notes \\
Lack of restitution speed \\
Lack of connectors \\
Unclear notes \\
Memory problems \\
\hline
\end{tabular}




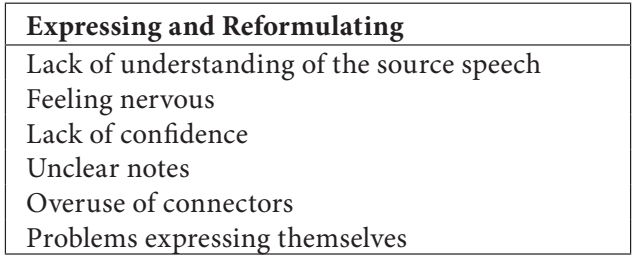

As shown in Table 3, the main problem during the listening phase in the case of both groups is lack of understanding. Significantly, all the 8 novice students and the 7 advanced students state that they have experienced problems with listening and understanding. The novice students also report a high percentage of problems related to what they describe as the poor sound quality of the recording, as well as difficulties with numbers, speed of delivery and a general unfamiliarity with the topic in hand. In the advanced students' group, apart from the lack of understanding, the most salient problems were the speed of delivery, numbers, and lack of attention or loss of concentration. A high percentage of advanced students also had difficulties with the unfamiliarity of the topic. The predominant differences occurring between both groups are related to problems with the sound (where novice students reported having encountered major difficulties) and lack of attention / concentration (reported only by the advanced students).

TABLE 3

Comparison of problems when listening to and understanding the original speech

\begin{tabular}{|l|c|c|c|}
\hline \multirow{2}{*}{ Listening - Understanding } & \multicolumn{3}{|c|}{ \% of students } \\
\cline { 2 - 4 } & Novice & Advanced & All students \\
\hline Lack of understanding & 100.00 & 100.00 & 100.00 \\
Numbers & 37.50 & 28.57 & 33.33 \\
Lack of common sense & 12.50 & 14.29 & 13.33 \\
Delivery speed & 37.50 & 42.86 & 40.00 \\
Unfamiliarity with the topic & 37.50 & 28.57 & 33.33 \\
Sound problems & 50.00 & 14.29 & 33.33 \\
Length of the speech & 12.50 & 14.29 & 13.33 \\
Information density & 12.50 & 14.29 & 13.33 \\
Lack of practice & 12.50 & 0.00 & 6.66 \\
Lack of attention / concentration & 0.00 & 57.14 & 26.66 \\
\hline
\end{tabular}

As regards note-taking (see Table 4), the speed of delivery of the original speech is the major difficulty encountered by both groups. However, there is an appreciable difference between the two groups, this problem being found to affect the novice students more than the advanced. Furthermore, the novice students pinpoint problems of lack of understanding of the original speech as directly affecting the quality of their note-taking. Other difficulties reported by the novice students, albeit to a lesser extent, are density of information and lack of practice. In the case of the advanced group, the only problems mentioned are related to the speed of delivery of the source speech and numbers, although in this case the percentages are in general lower than those for the novice group. It should be noted that advanced students do not mention lack of practice. 
TABLE 4

Comparison of problems when taking notes

\begin{tabular}{|l|c|c|c|}
\hline \multirow{2}{*}{ Note-taking } & \multicolumn{3}{|c|}{ \% of students } \\
\cline { 2 - 4 } & Novice & Advanced & All students \\
\hline Lack of understanding & 50.00 & 0.00 & 26.66 \\
Speed of delivery & 62.50 & 37.50 & 53.33 \\
Information density & 12.50 & 0.00 & 6.66 \\
Lack of practice & 12.50 & 0.00 & 6.66 \\
Numbers & 0.00 & 12.50 & 6.66 \\
\hline
\end{tabular}

When it came to decoding their own notes (see Table 5), the main difficulty encountered by the novice students was not being able to understand their own notes taken during the listening phase, which made it impossible to reconstruct the speech correctly. They also mentioned unclear notes (closely related to the previous point) and the lack of connectors.

Compared to the beginners' group, however, the advanced group placed more emphasis on the fact that unclear notes would make it more difficult to interpret them later. Furthermore, the advanced group stated that they did not encounter problems with the delivery speed. They were the only students who reported memory problems.

TABLE 5

Comparison of problems when decoding notes

\begin{tabular}{|l|c|c|c|}
\hline \multirow{2}{*}{ Reading notes } & \multicolumn{3}{|c|}{ \% of students } \\
\cline { 2 - 4 } & Novice & Advanced & All students \\
\hline Lack of understanding & 87.50 & 28.57 & 60 \\
Speed & 12.50 & 0.00 & 6.66 \\
Lack of connectors & 25.00 & 14.29 & 20.00 \\
Unclear notes & 50.00 & 71.43 & 60.00 \\
Memory problems & 0.00 & 14.29 & 6.66 \\
\hline
\end{tabular}

Expressing in the target language, along with the listening phase, is the point at which novice students encounter most problems (see Table 6). In addition to identifying expression problems in general, this group mentions very serious problems caused by a lack of clarity in their notes, a lack of understanding and being nervous. A noteworthy feature of this phase in relation to novice students is the appearance of problems related to feeling nervous and a lack of confidence, since this is the interpreting phase during which the student feels most exposed and is working under a great deal of pressure. As regards the advanced group, there is no overriding difficulty during this phase. As can be seen in Table 6, the difficulties mentioned are general problems of expression, unclear notes and a lack of understanding. However, the advanced students did not mention having problems with the overuse of connectors or with personal factors such as feeling nervous or lacking confidence. 
TABLE 6

Comparison of problems when expressing in the target language

\begin{tabular}{|l|c|c|c|}
\hline \multirow{2}{*}{ Expression } & \multicolumn{3}{|c|}{ \% of students } \\
\cline { 2 - 4 } & Novice & Advanced & All students \\
\hline Lack of understanding & 25.00 & 14.29 & 20.00 \\
Nerves & 25.00 & 0.00 & 13.33 \\
Lack of confidence & 12.50 & 0.00 & 6.66 \\
Unclear notes & 25.00 & 14.29 & 20.00 \\
Overuse of connectors & 12.50 & 0.00 & 6.66 \\
Expression problems & 37.50 & 14.29 & 26.66 \\
\hline
\end{tabular}

\subsubsection{Resolving interpreting problems}

To conclude the analysis of the problems, we studied the degree of success reported by the students at solving problems (corresponding to the question "Do you think you found a satisfactory solution?" in the questionnaire).

Students' answers were classified according to three categories, depending on whether the problem was solved satisfactorily, partially or left unsolved.

For each of the phases studied, we shall only analyse those problems on which the students provided information.

In the case of listening and understanding the overriding impression among all the students is that they have failed to deal with the task satisfactorily. This perception is more pronounced among the advanced students, of whom $57.10 \%$ state that they have not solved the task, whereas only $37.5 \%$ of the novice students report this problem. With regard to numbers, the advanced students also report greater dissatisfaction with their solution to the problem; none state that they have solved the problem correctly, whereas $66.70 \%$ of the novice students report having done so. When asked about the problems arising from the speed at which the original speech was delivered, $33.33 \%$ of the advanced students are satisfied with the solution they applied, compared to $66.70 \%$ of the novice students.

In the note-taking phase, there is a greater perception among the novice students of having satisfactorily solved the difficulty arising from the delivery speed of the original speech. As we can see from Figure 1, the advanced students report having only partially solved this problem $(66.70 \%)$.

FIGURE 1

Degree of resolution of the problem posed by the high speed of delivery during the note-taking phase

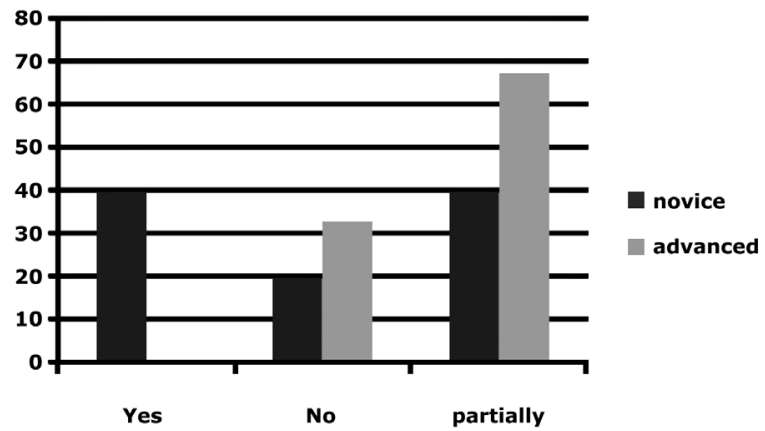


Also in relation to note-taking (see Figure 2), the majority of students in both groups who answered the question regarding the lack of connectors report that they have not found a solution (66.70\%). Interestingly, while the advanced students report no degree of resolution, $50 \%$ of the novice students report having found a partial solution. As for the clarity of their notes, $25 \%$ of both the advanced and the novice students state that they solved the problem. However, $50 \%$ of the novice students state that they failed to solve the problem, compared to $20 \%$ of the advanced students. At the same time, the advanced students also report a higher degree of partial solution $(50 \%)$ than the novice students (25\%).

FIGURE 2

Degree of resolution of the problem posed by the lack of clarity during the note-taking phase

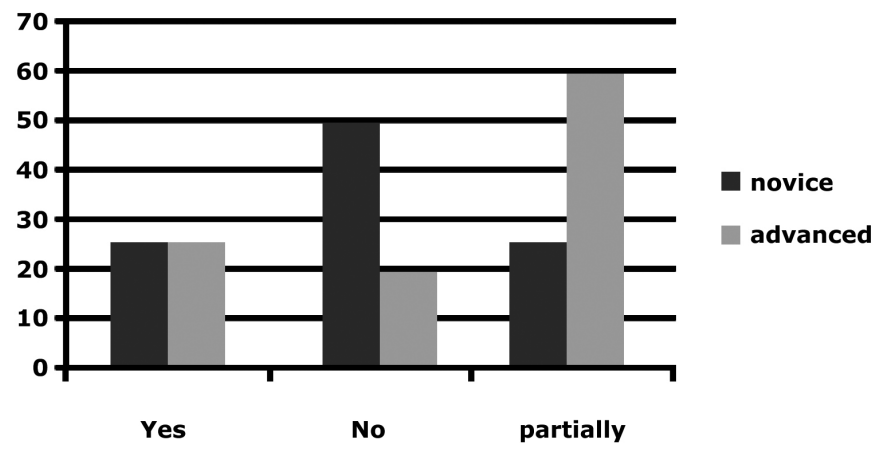

Regarding the expression phase, $100 \%$ of the students in both groups who answered the question state that they have not solved the problems posed by their lack of understanding.

\subsection{The interpreting strategies}

In Table 7, all the interpreting strategies used in both groups are listed. As specified in section 3.5, we have classified the strategies mentioned by the students in their answers for each of the consecutive interpreting phases.

We have considered strategies to include those actions on the part of the subjects requiring a greater degree of awareness and control in order to solve a difficulty (for example, paraphrasing, repeating, memorising or trying to calm down), as well as unconscious actions, in other words, those spontaneous reactions which occur naturally during the learning process without any degree of conscious control, such as, adding incorrect information. Thus, it is the researcher who interprets and classifies the corpus obtained from the point of view of the strategies used, while the subjects simply answer questions with the purpose of reflecting on how they believed they had solved a detected problem. 
TABLE 7

General breakdown of interpreting strategies

\begin{tabular}{|l|}
\hline Listening and Understanding \\
\hline Generalising \\
Omitting \\
Using common sense \\
Adding wrong information \\
Summarising \\
Paying greater attention to the source speech \\
Leaving in English (source language) \\
Paraphrasing \\
\hline Note-Taking \\
\hline Omitting \\
Generalising \\
Summarising \\
Adding wrong information \\
Resorting to memory \\
\hline Decoding Notes \\
\hline Adding wrong information \\
Omitting \\
Using common sense \\
Repeating \\
Resorting to memory \\
Speeding up the reformulation \\
Changing the order \\
Ignoring \\
\hline Expression and Reformulation \\
\hline Adding wrong information \\
Trying to calm down \\
Trying to avoid calques \\
Choosing the right vocabulary \\
Summarising \\
Omitting \\
Using common sense \\
Paying greater attention \\
\hline
\end{tabular}

The main strategies used by both groups of students when listening to and understanding the original speech are generalisation and omission (see Table 8). The main strategy used by novice students in the listening phase is to generalise, followed by omission and using common sense. In the advanced group the most common strategies are omission - used less frequently than in the novice group - and summarising, used more frequently than in the novice group. The strategies of paying greater attention and leaving the item(s) in English do not feature among the advanced students, who at the same time are the only ones to use the paraphrasing strategy. 
TABLE 8

Comparison of strategies when listening to and understanding the original speech

\begin{tabular}{|l|c|c|c|}
\hline \multirow{2}{*}{ Listening - Understanding } & \multicolumn{3}{|c|}{ \% of students } \\
\cline { 2 - 4 } & Novice & Advanced & All students \\
\hline Generalising & 87.50 & 28.57 & 60.00 \\
Omitting & 75.00 & 42.86 & 60.00 \\
Using common sense & 75.00 & 28.57 & 53.33 \\
Adding wrong information & 37.50 & 28.57 & 33.33 \\
Summarising & 25.00 & 42.86 & 33.33 \\
Paying greater attention & 12.50 & 0.00 & 6.66 \\
Leaving in English & 12.50 & 0.00 & 6.66 \\
Paraphrasing & 0.00 & 14.29 & 6.66 \\
\hline
\end{tabular}

When taking notes (see Table 9), the predominant strategy among all the students is summarising, although this strategy is still more prevalent in the group of advanced students. In contrast, the omission and generalising strategies emerge as the predominant options in the novice group. In the advanced group the strategy of summarising is followed by the strategy of resorting to memory. Finally, the advanced students mention omission and generalisation. While some novice students resort to adding wrong information, this strategy does not figure among the advanced students.

TABLE 9

Comparison of strategy frequency when taking notes

\begin{tabular}{|l|c|c|c|}
\hline \multirow{2}{*}{ Taking notes } & \multicolumn{3}{|c|}{ \% of students } \\
\cline { 2 - 4 } & Novice & Advanced & All students \\
\hline Omission & 37.50 & 14.29 & 26.66 \\
Generalising & 37.50 & 14.29 & 26.66 \\
Summarising & 37.50 & 57.14 & 46.66 \\
Adding wrong information & 12.50 & 0.00 & 6.66 \\
Resorting to memory & 12.50 & 28.57 & 20.00 \\
\hline
\end{tabular}

In the note-decoding phase (see Table 10), the predominant strategy when both groups are considered together is omission. Adding wrong information is the most frequently used strategy in the novice group, closely followed by omission and using common sense. Other strategies used by novice students are repetition, resorting to memory, speeding up the performance or changing the order in which the information appears in the speech. By contrast, the most frequently used strategy in the advanced group is omission, followed by the use of common sense, ignoring and resorting to memory. The main difference between the strategies of ignoring and omitting information lies in the fact that when the strategy of ignoring appears in the corpus, it is always reported as a conscious action on the part of the student, whereas omission may be either deliberate or unconscious. 
TABLE 10

Comparison of strategies when decoding the notes

\begin{tabular}{|l|c|c|c|}
\hline \multirow{2}{*}{ Reading notes } & \multicolumn{3}{|c|}{ \% of students } \\
\cline { 2 - 4 } & Novice & Advanced & All students \\
\hline Adding wrong information & 50.00 & .00 & 26.66 \\
Omission & 37.50 & 42.86 & 40.00 \\
Using common sense & 37.50 & 28.57 & 33.33 \\
Repetition & 12.50 & .00 & 6.66 \\
Resorting to memory & 12.50 & 14.29 & 13.33 \\
Speeding up the reformulation & 12.50 & 0.00 & 6.66 \\
Changing order of speech & 12.50 & 0.00 & 6.66 \\
Ignoring & 0.00 & 28.57 & 13.33 \\
\hline
\end{tabular}

With regard to expression in the target language (see Table 11), the most prevalent strategy used by advanced students is summarising. Although the low frequency of use of strategies by novice students, the strategy of adding wrong information is once again a distinctive feature. There is also a low frequency of use of strategies among the advanced students. Nevertheless, the predominant strategy of summarising is followed by omission and using common sense and paying more attention.

TABLE 11

Comparison of strategies at the expression phase

\begin{tabular}{|l|c|c|c|}
\hline \multirow{2}{*}{ Expression } & \multicolumn{3}{|c|}{ \% of students } \\
\cline { 2 - 4 } & Novice & Advanced & All students \\
\hline Adding wrong information & 25.00 & 0.00 & 13.33 \\
Trying to calm down & 12.50 & 0.00 & 6.66 \\
Trying to avoid calques & 12.50 & 0.00 & 6.66 \\
Choosing the right vocabulary & 12.50 & 0.00 & 6.66 \\
Summarising & 0.00 & 28.57 & 13.00 \\
Omission & 0.00 & 14.29 & 6.66 \\
Using common sense & 0.00 & 14.29 & 6.66 \\
Paying greater attention & 0.00 & 14.29 & 6.66 \\
\hline
\end{tabular}

\section{Discussion}

The descriptive study presented here allows the identification and classification of some of the problems and strategies found in consecutive interpreting at two different stages in interpreter training.

During the task, the novice students reported more problems than the advanced students, especially in the phases corresponding to understanding the original speech and taking down and decoding their notes. It is important to emphasise that the problems that crop up in each group tend to be different in kind. More techniquerelated problems emerge for the novice group, particularly when taking and decoding notes, and the same is true of more individual factors associated with feeling nervous or lacking confidence. Yet, it is surprising to find that both lack of attention and concentration problems related to memory during the note-deciphering stage only affected the advanced students. It is likely that the novice students, who have just begun to practise note-taking, are far too busy dealing with note-taking techniques to bear in mind that, along with their notes, memory, attention and concen- 
tration are also important skills when practising consecutive interpreting. It is possible that beginners mistake problems of lack of attention and concentration, which are truly at the root of their difficulties, for technical problems because, at that stage of training, they believe that the key lies in techniques, whereas as they advance, they realize that this is not the case. Nevertheless, it would be necessary to work with a larger sample size, as well as to consider other variables, in order to carry out a study with more statistical impact.

Regarding the students' perceptions concerning their ability to solve interpreting problems, the novice students report a greater ability to solve problems related to understanding the original speech. The advanced students show a greater perception of not having satisfactorily solved the task, both in problems related to numbers and those caused by the speed of delivery of the original speech. In the note-taking phase, the novice students express a greater perception of having satisfactorily solved the difficulty arising from the speed of delivery of the original speech. As for detecting a lack of connectors, whereas the advanced students express no degree of resolution, half of the novice students state that they have partially solved the problem. Regarding a lack of clarity in their notes, once again it is the novice students who report having failed to solve the problems stemming from this difficulty. Similarly, the degree of partial resolution expressed by the advanced students is greater than that reported by the novice students. One possible explanation for this general tendency of the advanced students to express less satisfaction with solving the problems may have to do with the fact that the more advanced the students are in the training process, the more critical they are of their performance. Their higher level of training is not necessarily reflected by a greater degree of confidence in their performance. In this context, we recall the contributions of Ericsson (2001) and Moser-Mercer, Frauenfelder et al (2000), previously mentioned, observing that the process whereby interpreter trainees progress to incipient expertise involves raising their strategic awareness, their capacity to reflect on the process and their critical awareness. Gile (2009) also advocates an explicit analysis of the strategic component, as opposed to approaches in which strategy acquisition is mainly a "trial-and-error" procedure, involving little or no analysis of processing capacity management.

Regarding strategies, the novice students tend to report a greater use of strategies than the advanced students, probably because students in the novice group also detect a larger number of problems. And perhaps because more advanced students have mastered and internalized a number of strategies to a sufficient extent that they are not aware of using them.

However, the advanced students have recourse to a wider range of strategies than the novice students. Sometimes both groups use the same strategy to solve the same kind of problem, and certain recurring patterns in the relationship between problems and strategies can be observed, as well as some remarkable differences. One noteworthy feature is that the novice group, who have received fewer hours of training, resort to adding wrong information, perhaps because the students are reluctant to leave a gap in their interpretation. They normally add information that they guess to be true or which, although not conveyed by the speaker's utterance, may be true. In the case of the advanced group, who have almost finished their training in consecutive interpreting, there is much more use of omissions, which is generally taken to be a less clumsy strategy than adding wrong information, but requires a certain 
amount of practice and decision-making to be able to use it effectively. The advanced students also resort more often to summarising and paraphrasing, which also require more practice and greater mastery of discourse analysis.

There are some commonalities among all the students when tackling certain problems. The recurrences found between both groups coincide with Gile (2009), who states that interpreters do not choose tactics or strategies at random. The author observes that the behaviour of trainees, as well as professional interpreters, follows certain "laws" or trends, which are sometimes conscious, but often unconscious. The recurrences that we have found in the corpus studied are as follows: when faced with the problem of a lack of understanding, a similar reaction can be seen across both groups when it comes to using omission, common sense and even summarising strategies. Faced with the problem of a source text delivered at an excessively fast speed, omission and summarising account for high percentages in both groups, but they then differ in their use of other strategies. When unclear notes are the source of the problem, there is a great deal of variability, but both groups coincide when it comes to the tendency to resort to memory and common sense. If there are sound problems, all the students concur over the action, deliberate or not, of paying greater attention. In cases where they do not manage to note down numbers, students from both groups tend to generalise when interpreting. When they detect the absence of connectors in their notes, both groups resort to using common sense. Regarding strategies used only by the advanced students, these are found mainly when it comes to reformulating in the target language. They are: summarizing, omitting, applying common sense and paying more attention.

\section{Conclusions}

This study shows a number of trends in the strategic actions taken by the students, depending on the level of training. Summarising the main results:

- Novice students report more problems than the advanced students;

- The problems that crop up tend to be different in kind, depending on the level of training;

- Regarding the students' perceptions concerning their ability to solve interpreting problems, advanced students show a greater sense of failure to satisfactorily resolve the task;

- There are some commonalities among all the students when tackling certain problems;

- Novice students tend to report a greater use of strategies than the advanced students;

- Advanced students draw on a wider range of strategies.

These results merit consideration in further studies, as we may hypothesise that a greater understanding of the problem-strategy relationship at different levels of interpreter training could have a direct impact on the development of methods and materials contributing to improvements in the teaching of consecutive interpreting.

Likewise, the fact that advanced students have a wider range of strategies at their disposal, which allow them to deal with a greater number of problems compared to novice students, suggests the importance of integrating into the firsts stages of the interpreting training the practice of identifying and consciously reflecting on interpreting problems, as well as investigating their causes. This practice can be expressly 
introduced by the teacher during training with a view to providing the students with resources which will enable them to self-regulate their interpreting performance and raise their awareness of the most challenging aspects of the process.

Furthermore, some results, such as the spontaneous use of particular strategies, indicate that special attention should be given to certain strategies in the classroom and to the corresponding teaching considerations, given their likely positive or negative repercussions on the training process.

Useful data can be elicited by encouraging the students to verbalise their strategies, thus giving them the opportunity to initiate the retrospection. In particular, it is a good way for the teacher to obtain first-hand information about the students' concerns and their main problems.

The study also allows us to pinpoint the adjustments necessary in future research. The pilot test verifies the overall appropriateness of the questionnaire in collecting data on the problem-strategy relationship. The instrument is simple to administer, and the data obtained can easily be processed and extracted for subsequent statistical analysis. One of the questions raised when the study was designed concerned the feasibility of retrospection. The study shows that relevant information was indeed remembered, although the subjects varied in the length and informativeness of their verbalisations. However, the study also reveals that the use of the questionnaire has certain limitations. We cannot totally be sure of how much information was missed. Repeating this kind of study in various, controlled, circumstances will help to circumvent this limitation. Moreover, there is usually an important degree of inaccuracy when questions about the processes involved are answered retrospectively. We had to discard a high percentage of incompletely answered questionnaires (11 out of 26). It should also be remembered that the questionnaire is static in nature; in other words, students are only able to answer the questions formulated by the questionnaire, whereas some other type of data-collection tool, such as interviews, focus groups or think aloud protocols, might possibly lead to other important information on the process followed.

Finally, we would like to stress that the results obtained in this study mark only the beginning of a more in-depth research project on the problem-strategy relationship. This will require an analysis of the internal consistency of the questionnaire used, as well as the inclusion of new variables in order to enlarge the available corpus. So it would be possible to analyse both the verbalisations of the subjects concerning the process itself (through interviews and questionnaires), and the objective documents resulting from the consecutive interpreting task (the recording of the students' interpreting performances and their interpreting notes). Similarly, with a view to achieving a larger sample size, future studies could incorporate a larger number of teaching centres throughout Spain, thereby increasing the sample and taking into account certain variables which may influence the results, such as the teaching methodology used at each institution and the academic and language background of the subjects.

In summary, future studies in the field of the problem-strategy relationship in consecutive interpreting will contribute to gain a better insight into how the processes involved in interpreting are acquired and developed, with a view not only to enhancing the teaching of the discipline, but also to providing advanced professional interpreters with the means to continue to improve the quality of their work. 


\section{ACKNOWLEDGEMENTS}

We would like to thank Maria Pearce, with whom we share many of the thoughts voiced in this study. We would also like to thank Jacqueline Minett for her readings and reviews.

\section{NOTES}

1. The Effort and Attention Model (Gile 1995) stresses the need for maintaining a balance when using mental capabilities in interpreting. It is based on the fact that interpreting mistakes derive from a series of difficulties throughout the process: speeches which are delivered fast, density of information, the restitution of proper nouns, a high density of technical terms, words that are confusing, figures, enumerations, etc.

2. In Spain the Licenciatura degree is one of the major higher-education degrees previous to doctoral studies. A Licenciatura typically requires from four to six academic years of University study. This system is in the process of being progressively changed to the Grado (Bachelor) and Master system in line with the Bologna Declaration on the European Higher Education Area.

3. The reception phase in consecutive interpreting includes those moments in the process when the interpreter perceives the original speech, decodes the material, retains a portion of the information in his/her working memory and notes down the linguistic and informative elements that he/she considers relevant to the proper completion of the task. The production phase includes those moments in the process when the interpreter calls on his/her long-term memory, reconstructs the structure and the information of the original speech and recodes the message in the target language (Gile 1995).

\section{REFERENCES}

Aвuín, Marta (2007): El proceso de interpretación consecutiva. Un estudio del binomio problemal estrategia. Granada: Editorial Comares.

ERICsson, K. Aanders (2001): Expertise in interpreting. An expert-performance perspective. Interpreting. 5(2):187-220.

FrASER, Janet (1996): The Translator Investigated. The Translator. 2(1):65-79.

GILE, Daniel (1995): Basic Concepts and Models for Interpreter and Translator Training. Amsterdam/Philadelphia: John Benjamins.

Gile, Daniel (2000): Opportunities in Conference Interpreting Research. In: Allison Beeby, Doris Ensinger and Marisa Presas, eds. Investigating Translation. Amsterdam/Philadelphia: John Benjamins, 77-89.

Gile, Daniel (2002): Conference interpreting as a Cognitive Management Problem. In: Franz Pöchhacker and Miriam Shlesinger, eds. The Interpreting Studies Reader. London: Routledge, 162-176.

GiLe, Daniel (2009): Basic Concepts and Models for Interpreter and Translator Training. Revised edition. Amsterdam/Philadelphia: John Benjamins.

Gran, Laura (1998): Developing Translation/Interpretation Strategies and Creativity. In: Ann Beylard-Ozeroff, Jana Kràlovà and Barbara Moser-Mercer, eds. Translators' Strategies and Creativity. Amsterdam/Philadelphia: John Benjamins, 145-162.

Hoffman, Robert (1997): The cognitive psychology of expertise and the domain of interpreting. Interpreting. 2(1/2):189-230.

Hönig, Hans G. and Kussmaul, Peter (1982): Strategie der Übersetzung. Tübingen: G. Narr.

Hurtado, Amparo (1999): Enseñar a traducir. Madrid: Edelsa.

Hurtado, Amparo (2001): Traducción y Traductología. Introducción a la Traductología. Madrid: Ediciones Cátedra.

Ivanova, Adelina (2000): The use of retrospection in research on simultaneous interpreting. In: Sonja TirkKonen-Condit and Riitta JÄÄskeläinen. Tapping and Mapping the Processes of Translation and Interpreting. Amsterdam/Philadelphia: John Benjamins, 27-52.

JakоBSEN, Arnt Lykke (2011): Tracking translator's keystrokes and eye movements with Translog. In: Cecilia Alvstad, Adelina Hild and Elisabet Tiselius, eds. Methods and Strategies of Process Research. Amsterdam/Philadelphia: John Benjamins, 37-56. 
Jiménez Ivars, Amparo (1999): La traducción a la vista: un análisis descriptivo. $\mathrm{PhD}$ research. Castellón: Universitat Jaume I.

Kalina, Sylvia (1994): Analyzing interpreters' performance: methods and problems. In: Mary Snell-Hornby, Franz Pöchhacker and Klaus Kainde, eds. Translation Studies: an Interdiscipline. Vol. 2. Amsterdam/Philadelphia: John Benjamins, 219-225.

Kalina, Sylvia (1998): Strategische Prozesse beim Dolmetschen. Tübingen: G. Narr.

Kalina, Sylvia (2000): Interpreting Competences as a Basis and a Goal for Teaching. The Interpreters' Newsletter. 10: 3-32.

Kalina, Sylvia (2002): Quality in interpreting and its prerequisites: a framework for a comprehensive view. In: Giuliana Garzone and Maurizio ViezzI, eds. Interpreting in the $21^{\text {st }}$ Century. Challenges and Opportunities. ( $1^{\text {st }}$ Conference on Interpreting Studies, Forlí, 9-11 November 2000). Amsterdam/Philadelphia: John Benjamins, 121-130.

Kiraly, Donald C. (1995): Pathways to Translation: Pedagogy and Process. Kent: The Kent State University Press.

Kohn, Kurt and Kalina, Sylvia (1996): The Strategic Dimension of Interpreting. Meta. 41(1): 118-138.

LöRsCher, Wolfgang (1991): Translation Performance, Translation Process, and Translation Strategies. A Psycholinguistic Investigation. Tübingen: G. Narr.

Moser-Mercer, Barbara (1997): Beyond Curiosity: Can Interpreting Research Meet the Challenge? In: Joseph H. Danks, Gregory M. Shreve, Stephen B. Fountain et al., eds. Cognitive Processes in Translation and Interpreting. Thousand Oaks: Sage, 176-205.

Moser-Mercer, Barbara, Frauenfelder, Uli H., Casado, Beatriz, et al., (2000): Searching to define expertise in interpreting. In: Kenneth Hyltenstam and Birgitta EnglundDimitrova, eds. Language processing and simultaneous interpreting. Amsterdam/Philadelphia: John Benjamins, 107-132.

Nord, Christiane (1988): Textanalyse und Übersetzen. Heidelberg: J. Groos Verlag.

Orozco, Mariana (2000): Instrumentos de medida de la adquisición de la competencia traductora: construcción y validación. PhD Research. Bellaterra: Universitat Autònoma de Barcelona.

RicCARDI, Alessandra (1996): Language-specific strategies. In: Cay Dollerup and Viveke APPEL, eds. New Horizons - Teaching Translation and Interpreting. Amsterdam/Philadelphia: John Benjamins, 213-221.

RiCCARDI, Alessandra (1998): Interpreting strategies and creativity. In: Ann BEYLARD-OzEroff, Jana Králové and Barbara Moser-Mercer, eds. Translators' Strategies and Creativity. Amsterdam/Philadelphia: John Benjamins, 171-179.

RicCARDI, Alessandra (1999): Interpretazione simultanea: strategie generali e specifiche. In: Caterina Falbo, Mariachiara Russo and Franceso Straniero, eds. Interpretazione Simultanea e Consecutiva: Problemi Teorici e Metodologie Didattiche. Milano: Ulrico Hoepli, 161-174.

RicCARDI, Alessandra (2005): On the Evolution of Interpreting Strategies in Simultaneous Interpreting. Meta. 50(2):753-767.

SunNari, Marianna (1995): Processing Strategies in Simultaneous Interpreting: Saying it All vs. Synthesis. In: Jorma Tommola, ed. Topics in Interpreting Research. Turku: University of Turku, Centre for Translation and Interpreting, 109-119.

SunNARI, Marianna (2003): Expert and novice performance in simultaneous interpreting: implications for quality assessment. In: Ángela Collados, María Manuela Fernandez SANCHEZ and Daniel GiLe, eds. La evaluación de la calidad en interpretación: investigación. Granada: Editorial Comares, 235-247. 


\section{APPENDICES}

Appendix 1: Speech interpreted by the students. Was the downfall of the Rapa Nui Civilization caused by a Biological Invasion?

In 1722 Captain Jacob Roggeveen, a Dutch seafarer, reached Easter Island. He found an island barren of trees and with a small, impoverished population, but there was clear evidence of a great, and recent, civilisation. The most startling evidence was the architecture and of course, the giant stone statues, or moai, which I'm sure you've all heard about. Ever since that first European brought back the news to Holland, historians have racked their brains and argued over the enigma of Easter Island, also known as "Rapa Nui" and "Isla de Pascua."

From about AD 400 to 1550, Rapa Nui's population increased from a small handful of people to about 7-9,000 inhabitants. Much of their culture, industry, building material, as well as their food supply depended on the palm forests that covered the island. The palms were Jubaea palms, endemic to the island and revered by the Polynesians, The Jubaea palms are now extinct.

From 1400 to 1600 the inhabitants industriously created the moai. Then abruptly, in the century before the first contact with Europeans, Rapa Nui society collapsed as deforestation, soil erosion, and a loss of biodiversity accompanied or even provoked bloody civil war. The islanders toppled all of the Moai. By the time Roggeveen found them, there were only about 200 people left on the island. The big question is, what triggered this disintegration?

Some scholars say it was a textbook example of population expanding until it overwhelms resources. However, archaeologists have now started to question the "over-exploitation" interpretation and point out that the civilization lasted for hundreds of years in reasonable ecological equilibrium with the resources of the island. This equilibrium was maintained with the same resource management techniques known elsewhere in Polynesia. So, if over-exploitation was not responsible, what was?

The Polynesians who colonized Rapa Nui accidentally brought with them the Polynesian rat. The Polynesian rat is a co-voyager, a vagrant, and is now found throughout the Pacific islands. It has been suggested that the rat was largely responsible for the extinction of a parrot endemic to Rapa Nui, this parrot fed on pollen and nectar. The parrot is believed to have been an important pollinator of the Jubaea palms. The rats also probably destroyed palm seeds and thus would have had a severe two-fold impact on forest regeneration. When the palms disappeared, the people could no longer make canoes to get fish, and thus lost their main source of protein. The cultural decline that followed may therefore have resulted more from disruption of both pollination and recruitment of tree species by invasive rats than from direct human over-exploitation of forest resources.

How credible is this hypothesis? Rats are responsible for more island extinctions than any other predators. They feed on eggs and chicks of birds nesting on the ground and in trees. On the Hawai'ian islands, rats caused abrupt waves of extinction that eliminated many native bird species simultaneously. The introduction of herbivorous mammals on islands may also have caused the rapid extinction of native plants.

We have heard that habitat destruction and fragmentation is the most important cause of biodiversity loss in the world. Invasions by exotic species are the second most important cause. And a huge proportion of those extinctions occur on islands, which are particularly vulnerable and prone to invasions. $93 \%$ of recently extinct species of amphibians and reptiles, $89 \%$ of birds, and $29 \%$ of mammals lived on islands.

In 1997, an international initiative to combat invasions by exotic species was put into place. A programme called the Global Invasive Species Programme or GISP, was developed to find ways of dealing with exotic invasive species. GISP is funded by the United Nations Environmental Programme and UNESCO, amongst others.

GISP will draw together the best management approaches for pest prevention and control and make these readily accessible to all nations, as well as lay the groundwork for new tools in science, information management, education, and policy. Unfortunately, its work is not without powerful opponents. The World Trade Organisation is not in favour of one of GISP's initiatives 
- to establish a "white list" of organisms that have been found to be non-invasive and therefore their movement should not be restricted.

All this may seem rather depressing and hopeless, but islands have some reasons for optimism if the resources are provided. Immigration can be controlled, and invaders can be detected. Eradication is difficult, but it has succeeded on some island invaders, and the spread of invaders can sometimes be halted. Resources could also be directed to rescue operations for endangered species, turning some islands into Noah's Arks of endemic endangered species.

\section{Appendix 2: Initial questionnaire}

- Affix ID label here:

- DATE:

- Age:

- Gender:

- What is your A language?

- Is English your A, B or C language?

- Do you have any training other than in translation and interpreting? Please give details:

- Do you have working experience in the field of translation and interpreting or any other?

\section{Appendix 3: Post-interpreting questionnaire}

- Affix ID label here:

- DATE:

- Before listening to the speech, and based on the introduction by the instructor, what came into your mind about this topic?

- Were they useful while rendering your speech?

- Did you have any previous knowledge on any of the mentioned subjects?

- Did you encounter any difficulties understanding when listening to the speech? Please specify:

\begin{tabular}{|l|l|l|l|l|}
\hline Description & $\begin{array}{l}\text { What do you think } \\
\text { this was due to? }\end{array}$ & $\begin{array}{l}\text { What did you } \\
\text { do about it? }\end{array}$ & $\begin{array}{l}\text { Do you think you found a } \\
\text { satisfactory solution? }\end{array}$ & $\begin{array}{l}\text { Other } \\
\text { comments }\end{array}$ \\
\hline & & & & \\
\hline
\end{tabular}

- What difficulties did you find when it came to taking notes?

\begin{tabular}{|l|l|l|l|l|}
\hline Description & $\begin{array}{l}\text { What do you think } \\
\text { this was due to? }\end{array}$ & $\begin{array}{l}\text { What did you } \\
\text { do about it? }\end{array}$ & $\begin{array}{l}\text { How was this reflected in } \\
\text { your notes? }\end{array}$ & $\begin{array}{l}\text { Other } \\
\text { comments }\end{array}$ \\
\hline & & & & \\
\hline
\end{tabular}

- What difficulties did you find when it came to reproducing your notes?

\begin{tabular}{|l|l|l|l|l|}
\hline Description & $\begin{array}{l}\text { What do you think } \\
\text { this was due to? }\end{array}$ & $\begin{array}{l}\text { What did you } \\
\text { do about it? }\end{array}$ & $\begin{array}{l}\text { Do you think you found a } \\
\text { satisfactory solution? }\end{array}$ & $\begin{array}{l}\text { Other } \\
\text { comments }\end{array}$ \\
\hline & & & \\
\hline
\end{tabular}

- Did you encounter any difficulties when it came to expressing ideas in the target language?

\begin{tabular}{|l|l|l|l|l|}
\hline Description & $\begin{array}{l}\text { What do you think } \\
\text { this was due to? }\end{array}$ & $\begin{array}{l}\text { What did you } \\
\text { do about it? }\end{array}$ & $\begin{array}{l}\text { Do you think you found a } \\
\text { satisfactory solution? }\end{array}$ & $\begin{array}{l}\text { Other } \\
\text { comments }\end{array}$ \\
\hline & & & & \\
\hline
\end{tabular}

- Did you have problems concentrating?

- Did your memory let you down at any point?

- Comment briefly on your presentation. Do you think it was adequate? 